\title{
OS PLANTIOS COMO EXPERIÊNCIA CRIATIVA: UM PRIMEIRO ENSAIO
}

\author{
Mariana Ciavatta Pantoja ${ }^{1}$ e \\ Amilton Pelegrino de Mattos $^{2}$
}

\begin{abstract}
Resumo
Neste artigo, ensaiamos uma primeira reflexão sobre os conhecimentos e práticas de cultivo agroecológicas de moradores da Reserva Extrativista do Alto Juruá (no extremo oeste do Estado do Acre). Os plantios, como são localmente designados esses experimentos, são abordados como uma experiência criativa de constituição de territórios de subjetivação nos quais processos de diferenciação são estabelecidos frente aos processos majoritários em curso, associados principalmente ao aumento da atividade agropecuária, e linhas de fuga são traçadas reforçando uma outra maneira de produzir subjetividades e conhecimento, como também a própria "Reserva". Exploramos a hipótese de que os plantios devem ser, portanto, conceituados dentro do regime de conhecimento local e, enquanto parte deste sistema, são uma sólida alternativa ao desmatamento na região.
\end{abstract}

Palavras-chave: Território. Desmatamento. Reservas extrativistas. Processo de subjetivação.

\footnotetext{
${ }^{1}$ Coordenadora do Laboratório de Antropologia e Florestas (Aflora), no Centro de Filosofia e Ciências Humanas da Universidade Federal do Acre, e pesquisadora do Projeto Nova Cartografia Social da Amazônia (PNCSA), Brasil. mariana.acre@gmail.com

${ }^{2}$ Pesquisador do Projeto Nova Cartografia Social da Amazônia (PNCSA) e do Laboratório de Antropologia e Florestas (Aflora/UFAC), Brasil. amiltonm@yahoo.com.br
} 


\title{
Plantations as CREATIVE EXPERIENCE: A FIRST TRIAL
}

\begin{abstract}
In this article, a first reflection on the knowledge and agro-ecological farming practices of residents of the Alto Juruá Extractive Reserve (in the far western state of Acre) is attempted. The plantations, as these experiments are locally called, are approached as a creative experience of establishing territories of subjectivation in which differentiation processes are established in view of major ongoing processes, mainly associated to increased agricultural activity. Lines of flight are traced reinforcing another way of producing subjectivities and knowledge, as well as the «Reserve» itself. The hypothesis explored is that the plantations should therefore be conceptualized within the regime of local knowledge and, as part of this system, are a solid alternative to deforestation in the region.
\end{abstract}

Keywords: Territory. Deforestation. Extractive Reserves. Process of Subjectivation.

\section{INTRODUÇÃO}

s florestas e rios da região do Alto Juruá acriano, e do estado do Acre de
maneira geral, foram ocupados por trabalhadores-migrantes nordestinos
no final do século XIX, em meio a confrontos de diversas naturezas com as populações indígenas nativas (IGLESIAS, 2010; PANTOJA, 2008; WOLFF, 1999). A instalação progressiva dos seringais ao longo dos rios e afluentes fez com que estes novos moradores, desde então, se tornassem conhecidos como "seringueiros", numa referência explícita à atividade de produzir borracha a partir do "corte da seringa" (extração do látex da seringueira, Hevea brasiliensis). Mas esta denominação escapou das determinações puramente econômicas e se tornou uma auto-designação referida a uma forma de manejo territorial-florestal e de organização social que comportava, por um lado, seringais, patrões e barracões; e, por outro lado, colocações, famílias e parentesco (ALMEIDA, 1991; PANTOJA, 2008).

Nos anos de 1980/90, foi erigida em identidade política pelo movimento social que criou o Conselho Nacional dos Seringueiros e defendeu a bandeira das Reservas Extrativistas (ALMEIDA, 1995; ALLEGRETTI, 2002). Mais recentemente, no século XXI, com a incontornável crise de preços e de mercado para borracha nativa amazônica, a atividade agrícola (e pecuária) dos seringueiros, que sempre existiu (PANTOJA et al., 2002), ganhou maior peso como rendimento monetário dos grupos domésticos, causando certo alarme entre cientistas e gestores públicos 
de Reservas Extrativistas e unidades de conservação afins (ERINGHAUS; GOMES, 2008; PANTOJA; COSTA; POSTIGO, 2009).

Neste artigo queremos refletir justamente sobre os conhecimentos e práticas de cultivo dos moradores da Reserva Extrativista do Alto Juruá (doravante "Reserva") como uma alternativa aos processos de desmatamento. Estaremos nos referindo mais especificamente às experiências localmente denominadas de plantios: áreas onde são cultivadas, de forma combinada, fruteiras, palmeiras e árvores (espécies madeireiras), as duas últimas nativas da floresta. Este núcleo de gêneros e espécies vegetais comumente consorciados poderá, por sua vez, estar associado a outros típicos de roçados, como a macaxeira, a cana e as bananas. Embora o termo técnico para este tipo de plantação seja "sistema agroflorestal", o evitamos aqui propositadamente já que o mesmo não é de uso corrente entre os nossos interlocutores, que falam antes dos seus plantios.

Partimos do princípio que os plantios, claro, remetem ao ato de plantar e ao que é efetivamente plantado, mas também, e principalmente, para nossos objetivos aqui, à criação de um território cuja definição se assenta sobre as relações que nele, ou a partir dele, têm lugar. É neste sentido, a nosso ver, que os plantios são uma experiência criativa: neles são propostas experimentações agroecológicas cujo sentido ultrapassa em muito a eficácia técnica, sediando antes processos de subjetivação bastante amplos, como procuraremos indicar. Em sintonia com as formulaç̧ões críticas de Márcio Goldman (2009), feitas a partir da constatação de um recorrente apego por parte das etnografias às categorias consagradas teórica e politicamente, parece-nos que, mais do que definir para si uma identidade estabilizada (como a de "agroflorestais"), as formulações de nossos interlocutores contém antes um frescor e uma flexibilidade próprios do cotidiano. Elas apontam para a constituição dos plantios como "territórios existenciais", a partir dos quais "linhas de fuga" são traçadas para escapar de processos majoritários em curso, e repor um sentido de "Reserva". ${ }^{3}$

\footnotetext{
3 "Pois nas lutas ligadas às noções de identidade ou cultura há algo mais do que esforços para criar e sustentar identidades ou para inventar e afirmar culturas: há o movimento que é aí produzido, não importando apenas as tentativas identitárias ou culturalizantes mas, também, e talvez principalmente, as linhas de fuga que são aí traçadas e os territórios existenciais que são aí construídos." (GOLDMAN, 2009, p. 16) Para um aprofundamento desta discussão, ver Viveiros de Castro e Goldman (2008).
} 
Talvez algumas palavras sejam necessárias sobre o contexto no qual se inserem os plantios e o trabalho de pesquisa que embasa este artigo.

Em 2008, numa iniciativa que reuniu a Comissão Pró-Índio do Acre (CPI), o Laboratório de Antropologia e Florestas (Aflora/UFAC), os antropólogos Mauro Almeida (Unicamp) e Manuela Carneiro da Cunha (então na Universidade de Chicago), e a Associação Apiwtxa do povo Ashaninka do rio Amônia, que recém-criara o Centro Yorenka Antame (Saberes da Floresta), dois projetos foram elaborados dentro de um edital do Funbio/Arpa. ${ }^{4}$ Entre esses parceiros era consenso que diante de uma forte tendência agropecuária na Reserva e um quadro crescente de desmatamento, da crise institucional da entidade de representação dos moradores, e de sérios conflitos na fronteira com o Peru (extração ilegal de madeira, tráfico de drogas), vividos principalmente pelos Ashaninka, era necessária uma ação minimamente articulada visando estimular outros motes de organização e de alternativa de vida para os moradores da Reserva, reverter 0 quadro de crise que se implantara, e também fortalecer o Centro Yorenka Antame como um pólo regional de produção de conhecimentos e práticas gestados dentro da floresta.

Se nas Terras Indígenas da região o trabalho da CPI ao longo de quase três décadas lograra consolidar uma situação mais favorável do ponto de vista do fortalecimento das práticas tradicionais de manejo do território, na Reserva a situação era outra, comprometendo inclusive a efetividade do trabalho realizado nas Terras Indígenas, suas vizinhas. Uma ação coordenada e inovadora, concordaram os parceiros, era, portanto, uma prioridade. Tanto o projeto apresentado pela CPI quanto o da Apiwtxa se assentaram sobre a difusão de práticas agroecológicas e enxergavam na reaproximação entre os moradores da Reserva e das Terras Indígenas uma estratégia promissora, além de uma oportunidade de restaurar laços de contato e trocas que já haviam sido mais freqüentes nos anos de 1990, auge da Aliança dos Povos da Floresta (BERNO DE ALMEIDA, 1989).

\footnotetext{
${ }^{4} 0$ Centro Yorenka Antame foi criado em 2007 a partir da experiência desenvolvida pela Apiwtxa na Terra Indígena Kampa do Rio Amônia, no Município de Mal. Thaumaturgo (onde também se localiza a Reserva), tendo como objetivo se constituir num pólo de formação, educação e difusão de práticas de manejo para a região do Alto Juruá. 0 Fundo Brasileiro para Biodiversidade (Funbio), dentro do Programa de Áreas Protegidas (Arpa), lançou um edital, também em 2007, destinado às iniciativas de trabalho junto aos moradores do entorno de Unidades de Conservação de Uso Indireto, entre elas o Parque Nacional da Serra do Divisor, que também incide no Município de Mal. Thaumaturgo.
} 
Os dois projetos foram aprovados, tendo ambos os autores deste artigo se envolvido com o projeto executado pela CPI..$^{5}$ Este último, na Reserva, por meio de uma gestão descentralizada, convidou para coordenador-técnico local Antonio Teixeira da Costa, o "Caxixa", antigo seringueiro e experiente agricultor que logrou, ao longo de sua vida, conhecer, desenvolver e adaptar técnicas de cultivo próprias aos sistemas agroflorestais, e em geral desconhecidas dos moradores da Reserva (como o trabalho com mudas e o enxerto, por exemplo). Incentivador da diversificação dos cultivos visando a alimentação e a conservação da floresta, Caxixa fez de seus locais de moradia sítios ${ }^{6}$ experimentais, recuperando capoeiras e pastagens, plantando uma grande diversidade de fruteiras e "essências madeireiras", e recebendo todos que ali chegassem para conhecer, experimentar os frutos e levar para casa alguma muda ou semente. Nos últimos anos passou a vender algumas de suas produções na sede do Município. Como técnico com contratos temporários na Secretaria Municipal de Agricultura, estimulou e criou uma feira de venda direta do produtor agrícola ao consumidor, além de percorrer regularmente toda Reserva prestando assistência técnica, visitando as famílias e ministrando cursos de fabrico de farinha e seus derivados. Com o passar dos anos, tornou-se, assim, uma referência no município.

Hoje, após três anos de trabalho e tendo o "projeto Funbio" encerrado formalmente suas atividades, observa-se, por um lado, uma demanda pela continuidade do apoio ao trabalho com plantios, que agora já reúne uma rede de famílias em sete localidades da Reserva e conhece uma institucionalização mínima com a criação, em novembro de 2011, na reunião de encerramento do projeto, do "Grupo Agroflorestal Vida e Esperança". Mas, por outro lado, este mesmo trabalho desde sempre já transbordara os limites de qualquer planejamento.

Aoseu início, em 2008, o grupo quepassou a trabalharmaissistematicamente com Caxixa foi composto por pessoas, famílias, já dele conhecidas e que na verdade já estavam de diversas maneiras envolvidas com plantios. Algumas já tinham um começo, outras muita vontade e interesse, e outras ainda começavam a repensar 0 gado como alternativa de vida e queriam recuperar áreas ocupadas com pastagem.

\footnotetext{
${ }^{5}$ Mariana Ciavatta Pantoja como co-coordenadora, e Amilton Pelegrino de Mattos em reuniões e viagens de campo.

6 "Sítio" pode designar tanto uma área específica de plantios, quanto a totalidade de uma localidade com plantios, como o Sítio Alan Delon, pertencente a Antonio Caxixa, e uma homenagem ao seu filho caçula.
} 
Em cōmum, uma desidentificação em relação a processos majoritários em curso na Reserva, em especial aqueles com efeitos de desmatamento, nos quais predominam agricultura e pecuária associadas à proliferação de "fazendas" e de núcleos populacionais adensados (PANTOJA et al., 2009).

Essa dinâmica de "propagação sem planejamento prévio" permaneceu durante a execução do projeto, e permanece agora, ao seu término, afirmandose como uma maneira de fazer, como um regime de produção de conhecimento próprio. Para além das famílias formalmente envolvidas, saquinhos de muda, orientações e visitas vão sendo trocados nas vizinhanças, expandindo a rede Vida e Esperança num rizoma cujas conexões são difíceis de prever, mas se sabe que elas acontecerão. Visitas que comem frutas e ao sair levam sementes ou saquinhos de muda, solicitações de vizinhos que querem também iniciar um plantio, doações de mudas a pessoas nas quais se percebe uma vocação ou interesse autêntico, uma conversa aqui, outra acolá, enfim, situações diversas do dia a dia que, muito embora não constem de planilhas de atividades, instauram novos territórios, ou militam para esta instauração.

\section{Criando Territórios}

Na localidade conhecida por Alegria, dois casais, sob orientação de Antonio Caxixa, fazem seus plantios: trata-se de Belo e Antonia, e de Raimundo e Eliéti. Ambos têm filhos, todos ainda pequenos, o que significa que a força de trabalho é mesmo a do marido e da esposa. Mas as crianças ajudam, como sempre ocorre na economia camponesa florestal (ALMEIDA, 1986), desta vez enchendo saquinhos, colocando semente neles e participando da repicagem das mudas. Parece pouco, mas não é. 0 trabalho com os plantios, em especial em sua fase inicial, é delicado, mas volumoso; talvez quase divertido, muito propício à participação das crianças.

No Morro da Glória, as mulheres Natália e Zélia iam com os filhos para a área do plantio e lá passavam o dia peneirando a terra, enchendo saquinhos e neles acondicionando as sementes. Na aldeia Kuntanawa mais próxima à vila Restauração, José Osmildo (conhecido como 0́) recebeu os alunos da escola para uma aula prática sobre "sistemas agroflorestais", e habilmente introduziu a atividade de encher saquinhos, premiando a garotada com uma bala a cada saquinho pronto. É esta atividade que vai viabilizar as mudas, que serão depois 
transplantadas para a terra ou doadas para vizinhos interessados, principal forma de expansão do trabalho complantios.

Na foz do Acuriá, quando lá chegamos em fevereiro de 2012, as três jovens mães de família do lugar, com seus filhos, levaram-nos a conhecer os plantios no entorno das casas, que ali surgiram diante dos nossos olhos como um espaço de extensão do universo doméstico, tal como o terreiro. Enquanto caminhávamos por entre as plantas de diferentes espécies, as mulheres nos apresentavam o trabalho e contavam como tudo havia sido feito, e as crianças iam correndo na frente, subindo nas árvores, comendo e oferecendo-nos frutas. Mas e os homens, onde estavam? Dentro do igarapé Acuriá, onde estão os roçados das famílias e outras áreas de plantio, locais de trabalho principalmente masculino, pois distante das residências, estas, via de regra, de autoridade feminina.

Para implantação dos plantios, se há uma etapa de limpeza do local, não se trata do preparo do terreno para um roçado, que requer várias etapas (brocar, derrubar, queimar, encoivarar) e uma transformação maior (ou mais brusca) da paisagem. Nos plantios a área prioritária são as capoeiras, com a vantagem de que não precisam ser desbastadas inteiramente. Basta que haja espaço para 0 desenvolvimento das mudas, sejam elas fruteiras ou "essências madeireiras". Há casos, como o do sítio de Antonio Caxixa, em que por vezes ele simplesmente abriu piques na capoeira para plantar, mantendo a vegetação pré-existente quase intacta, cuidando apenas que ela não sufocasse as espécies introduzidas. 0 resultado são capoeiras extremamente enriquecidas e que funcionam como uma espécie de incubadora: quando as plantas introduzidas estiverem mais desenvolvidas, o mato será roçado e a paisagem do plantio trabalhada. Uma espécie de jardinagem florestal. 0 mesmo pode ocorrer com roçados: junto com o "custeio", espécies perenes serão introduzidas, e ali permanecerão quando as de ciclo mais curto forem retiradas. Bananais também podem ser transformados em plantios.

Chama atenção, portanto, a formação de uma paisagem nova - a dos plantios - que será criada num trabalho coletivo e que pode lembrar o de um paisagista. A paisagem existente, seja ela uma capoeira, um roçado, um bananal ou mesmo uma pastagem, será remodelada com a introdução de espécies de caráter mais permanente e de forma combinada, ou consorciada. As possibilidades parecem ser inúmeras, e as experiências se multiplicam. Não há, assim, necessariamente um padrão para localização dos plantios (se perto ou longe da casa), para o terreno de implantação dos mesmos (capoeira roçada, ou não, 
pastagens, bananais) ou para as escolhas e combinações possíveis entre as espécies cultivadas.

Notamos que entre as madeiras, o aguano (ou mogno) é o preferido, praticamente todos têm uma quantidade significativa desta espécie plantada. Mas cedro, cumaru, mesmo a seringueira, e outros, também são encontrados num ou noutro plantio. Palmeiras nativas, como o açaí, patoá, abacaba e buriti são hors concours. Há verdadeiros jardins de açaís e buritis, por exemplo, em áreas mais úmidas. Cítricos, quase todos, e há um fascínio pela técnica de enxerto. 0 abacaxi e a ingazeira são quase que o primeiro passo na constituição dos plantios, enriquecendo o solo e criando condições mais adequadas para que as demais espécies possam vingar. ${ }^{7}$ É possível ainda ter mais de um sítio, ou seja, locais onde é possível ao responsável pelo trabalho idealizar projetos diferentes entre si, o que significa que numa mesma localidade familiar pode haver mais de um sítio em diferentes estágios de desenvolvimento e com diferentes composições e propósitos. Zé Magro, no rio Caipora, por exemplo, planeja fazer "um seringal" de seringueiras plantadas, não tanto para produzir, embora não descarte esta possibilidade, mas como uma espécie de museu vivo para que seus filhos e netos possam conhecer e apreciar. "Acho bonito", arrematou.

Trata-se de criar territórios inusitados, ou de alguma forma personalizados, como uma atividade de paisagismo. Um outro exemplo seria o jardim de buritis e açaís que Caxixa concebeu e executou, isto é, plantou de uma certa maneira, considerando questões técnicas (como o terreno alagadiço, distância adequada entre espécies), práticas (como fartura de alimentos perto de casa, possibilidades futuras de venda) e estéticas, estas de cunho mais pessoal. Ao lado da sua antiga casa de farinha ele plantou há alguns anos muitas qualidades de pupunha, hoje uma bela paisagem destas palmeiras com frutos de várias cores e tamanhos, como uma floresta bosqueada onde se pode caminhar com tranquilidade, e onde vários animais costumam vir se alimentar. 0 caminho para sua cacimba é uma sucessão de ambientações: um baixo com buritis, em seguida uma área de cítricos na qual literalmente se atravessa por dentro de um limoeiro, abacaxis aqui e ali, abacateiros, e finalmente, já perto da fonte, palmeiras diversas. Os plantios de

\footnotetext{
${ }^{7}$ Entre as frutas cultivadas, além das já citadas no corpo do texto, encontramos limão, laranja, tangerina, lima, abacate, beribá, cupuaçu, graviola, banana, goiaba, acerola, mamão, maracujá, caju, coco etc. Várias delas, como, por exemplo, a banana, ocorrem em diversas qualidades.
} 
Eliéti e Raimundo guardam uma surpresa bem em seu interior: um jardim de flores, que a jardineira por ele responsável batizou de "jardim da abelha".

Em franco contraste com plantios estão as pastagens, cuja única forma de vida que vinga é o capim. Mesmo palheiras costumam ser derrubadas. Ora, ninguém come capim, como observaram criticamente vários de nossos interlocutores. Os plantios, ou reflorestamento, portanto, desafiam as pastagens, e o desmatamento. À destruição da vida, ou a imposição de uma só vida, de uma só paisagem, o trabalho complantios recria vidas, as multiplica, afirma a diversidade cênica, a fartura alimentar e projeta um meio de vida outro.

É interessante observar que a constituição de plantios parece apontar para um exercício de conhecimento ao qual nossos interlocutores se entregam com gosto. A busca por sementes e mudas ainda inéditas nos sítios cultivados é quase uma obsessão, a meta é a diversificação. Nenhuma oportunidade é perdida neste sentido: seja em Rio Branco, seja numa localidade as margens do rio Juruá, provar uma fruta que não se conhece implica em, no momento seguinte, pedir a semente para plantar e informações sobre a espécie e seu cultivo. Em casa, a experiência de plantar, escolhendo o local, preparando a terra e acompanhando o desenvolvimento. Se a muda vinga, outras serão assim que possível reproduzidas e, com o tempo, repassadas aos demais com o conhecimento adquirido sobre a experiência. É neste "fazer" (experiência e transmissão) que o conhecimento relativo aos plantios se produz e reproduz. ${ }^{8}$

Se o conhecimento é uma das motivações para os plantios, há outras também. A garantia de uma alimentação farta, diversificada e/ou saudável, em especial para os filhos, aparece em todas as falas. Zélia, que por motivos pessoais teve que abandonar sua casa no Morro da Glória, conta, por exemplo, que seu filho costuma chorar perguntando por quê não podem voltar para casa, onde há fartura de frutas para ele comer; ao contrário da vila Thaumaturgo, escassa em frutas e que, quando aparecem, precisam ser adquiridas mediante troca monetária. Poder alimentar não só a família, mas também oferecer a visitantes que aparecem, sejam das redondezas ou de mais longe, também é apontado como motivação, o que reforçaria uma socialidade apoiada na reciprocidade de alimentos (como o

${ }^{8}$ Sobre a noção de "conhecimento tradicional", leia-se em Carneiro da Cunha e Almeida (2002, p. 14) que ele [o conhecimento local] "envolve por um lado pesquisa, experimentação e observação; por outro, envolve raciocínio, especulação, intuição. Supõe prática constante e, enfim, muita troca de informação". 
café na chegada, convites para refeições, e mesmo a vizinhança de carne de caça). Evitar que os filhos "mexam no que é alheio" (no caso, fruteiras) e ocasionem conflitos com os vizinhos seria outra função social, digamos assim, dos plantios. 0 comércio também aparece no horizonte de motivações. Muitos se espelham no exemplo de Caxixa, que já há alguns anos vende produtos de seu sítio na vila (como limão, pupunha, abacaxi, tomate, abacate, entre outros).

\section{A Geopolítica dos Plantios}

Logo no início de nossas reflexões para este artigo, nos propúnhamos a seguinte distinção: entender em que medida a ideia de território - na fala, no pensamento e nos processos políticos expressos por nossos interlocutores a partir da experiência local de 20 anos da Reserva Extrativista do Alto Juruá -, não se confunde com a noção de região, esse produto de saberes outros - de ciências, tecnologias e poderes do Estado (ALMEIDA, 1995). A impressão que tínhamos, ao ouvir nossos interlocutores 20 anos depois da "criação" da Reserva, é que ela estava, em vez disso, "se criando", ou que ela está por "se criar", ainda e sempre, ali: nos conflitos, nos estranhamentos em relação às políticas de gestão do Estado e dos poderes locais, mas também e principalmente nas alternativas que eles, esses nossos interlocutores, podem dar para tudo isso, na maneira de elaborarem uma posição que ainda sustenta um projeto de Reserva, na sua forma de produzir território. ${ }^{9}$

Há, é verdade, um tom que prevalece na produção da "Reserva" e que remete a uma retórica baseada na vitimização, isto é, que apela aos decretos e leis, que reclama a presença de órgãos e funções públicas para que ele venham restaurar uma legalidade que parece perdida frente a um quadro crescente de ações ilegais (grandes pastagens, comercialização de madeira e carne de caça, derrubada das matas ciliares, caçadas e pescarias com métodos predatórios), pois que contrárias ao principal instrumento de gestão local, o Plano de Utilização. ${ }^{10}$

${ }^{9}$ Cabe lembrar, neste sentido, que no contexto do contato com pesquisadores e agentes do Estado
para a produção da Reserva (e dos extrativistas) esses saberes locais e sua ciência da mistura passou
a compor com novos elementos e se hibridizar com um pensamento purificador (LATOUR, 1994).
Nos últimos 10 anos, outro regime de conhecimento entra em cena com o Centro Yorenka Antame,
sendo Benki Pianko seu principal artífice, e começa a permear os discursos locais, como o de
Caxixa.
${ }^{10} 0$ Plano de Utilização é um conjunto de leis, apoiadas sobre o direito costumeiro e a legislação 
Porém, pudemos observar também a operação de outros recursos, nos quais a lógica do Estado, ou da ciência, não impera e que encerram, por isso mesmo, um efeito desestabilizador (GOLDMAN, 2009, p. 12). Geralmente esses outros recursos estão associados à criatividade, e são eles que estamos perseguindo neste artigo.

Assim, no início, partimos da distinção dado/construído, ou região/ território, ou ainda Estado/agentes locais. Poderíamos dizer que a maneira de construir o território, ou sua natureza cultural como algo que é construído, não se confunde com a região, a porção de espaço homogênea medida em latitudes e longitudes e representada nos desenhos dos mapeamentos oficiais, enfim: o dado. 0 que poderíamos fazer? Pensamos então em afirmar o território e suas práticas de produção, sobre a ficção da região, esse produto leviatânico.

Porém, percebemos pouco a pouco que afirmando a produção de território como construído, contra-produzíamos o dado, a natureza, a região. ${ }^{11}$ Essa confusão, inclusive, dava-se pelo fato da geopolítica de nossos interlocutores há muito já vir enfrentando a geopolítica majoritária e oficial e, assim, apropriandose de seus recursos, entre eles a própria ideia de natureza (o que suporia que eles têm o mesmo "dado" que nós). Mas, tal como a noção de "cultura" apropriada por nossos interlocutores, tampouco a apropriação da noção de "natureza" bastaria para reduzir a capacidade de misturar de sua ciência cabocla, que reforça uma outra maneira de fazer, de produzir a si e a Reserva. Pelo contrário, a apropriação desses termos noutros contextos serve tanto para uma disseminação polissêmica, como para domar, para amansar esses conceitos.

Vimos, portanto, que precisávamos traçar uma rota de fuga para escapar da armadilha relativista, que supõe um dado, a região, a partir do qual diferentes constructos (territórios) são afirmados. ${ }^{12}$ Sem negar a eficácia política de tal via, buscávamos outra, não menos política, guiados por nossos interlocutores, que amansam nossos conceitos ao deles se apropriar e criam territórios a partir de outra chave epistemológica [suporte de conhecimento], quiçá ontológica. ${ }^{13}$ Nossos

ambiental, que objetivam regular o uso e acesso aos recursos naturais das Reservas Extrativistas. Ver, por exemplo, Carneiro da Cunha e Almeida (2002, p. 143-146).

${ }^{11}$ Sobre esta dinâmica de produção e contra-produção, ver Wagner (2010).

${ }^{12} \mathrm{Na}$ verdade, o pensamento convencional suprime o dado do nativo (sua natureza seria a mesma que a nossa), supondo que ele só teria cultura, ou elaboração simbólica sobre este dado supostamente comum (VIVEIROS DE CASTR0, 2002).

${ }^{13}$ Sobre usos não-convencionais de categorias consagradas pela ciência, ver, por exemplo, Carneiro

OS PLANTIOS COMO EXPERIÊNCIA CRIATIVA...

M. C. Pantoja e A. P. de Mattos

- 163 
interlocutores se apropriam do que chamamos de natureza (aspeando-a, digamos assim), enchendo-a de subjetividades e agências, de simbioses com algo que é vivo e com o qual se relacionam. Se na agricultura tradicional não-indígena isso não é muito comum, nas práticas de plantio parece ser possível encontrar uma proliferação de subjetividades. E isso tem claramente uma dimensão política: 0 discurso que subjetiva a "natureza" está num contexto de destruição da natureza.

\section{Os Plantios como Zonas de Vizinhança}

De certa maneira, é preciso começar pelo fim: todos os devires já são moleculares. É que devir não é imitar algo ou alguém, identificar-se com ele. Tampouco é proporcionar relações formais. Nenhuma dessas duas figuras de analogia convém ao devir, nem a imitação de um sujeito, nem a proporcionalidade de uma forma. Devir é, a partir das formas que se tem, do sujeito que seé, dos órgãos que se possui ou das funções que se preenche, extrair partículas, entre as quais instauramos relações de movimento e repouso, de velocidade e lentidão, as mais próximas daquilo que estamos em vias de nos tornarmos, e através das quais nos tornamos. É nesse sentido que o devir é o processo de desejo. Esse princípio de proximidade ou de aproximação é inteiramente particular, e não reintroduz analogia alguma. Ele indica o mais rigorosamente possível uma zona de vizinhança ou de co-presença de uma partícula, o movimento que toma toda partícula quando entra nessa zona. [...] A vizinhança é uma noção ao mesmo tempo topológica e quântica, que marca a pertença a uma mesma molécula, independentemente dos sujeitos considerados e das formas determinadas (DELEUZE; GUATTARI, 1997, p. 64; grifo do autor).

Num contexto como o que se encontra a Reserva (de crise de identidade dos próprios extrativistas, de política ambiental adversa por parte das esferas federal, estadual e municipal, do sentimento de indignação e impotência diante das recorrentes infrações, do crescimento desenfreado das fazendas de gado), os plantios são, sobretudo, práticas de conhecimento que se articulam como territórios de subjetivação (GOLDMAN, 2009). E nesses territórios, a nosso ver, interessa menos o que se é do que o que não se é: fazendeiro, caçador predatório, explorador de madeira. Ao afirmarem a diferença, nossos interlocutores escapam da

da Cunha (2009). Sobre a noção de ontologia e de "guerras ontológicas", ver Almeida (2007). 
redução operada pelo conhecimento convencional (WAGNER, 2010) que afirma a universalidade, o relativismo, os divisores. É o regime de conhecimentos sustentado pelos plantios que permite a diferenciação das subjetivações majoritárias.

É fato que os plantios até poderiam ser pensados como uma reafirmação do projeto de identidade extrativista - e pode mesmo ser que a designação "agroflorestal", trazida "de fora" e alvo provável de políticas públicas, tenda a apontar nesta direçã 0 . . No entanto, insistimos, nosso esforço aqui é outro: tratase de pensar os plantios dentro de um movimento de diferenciação, que nega as alternativas que vem sendo apresentadas seja pelo órgão estatal gestor da Reserva, seja pela Associação de moradores, pelo poder público municipal ou pelos agentes locais que insistem agir como "patrões", como é o caso dos fazendeiros. 0 que se cria nos plantios não é propriamente uma identidade de plantadores (como "agroflorestais", por exemplo). Talvez o termo de identificação coletiva não seja, ao menos ainda, o mais importante, e sim o exercício de uma subjetividade criativa, que sabe reconhecer seus inimigos e, por outro lado, estabelecer alianças.

Os plantios também são conhecidos localmente como reflorestamento, o que chamou nossa atenção para as relações que contextualizam o território assim conceituado: de um lado, tem-se o espaço domesticado e estável da casa, do terreiro e da família, e, de outro, o espaço do selvagem e da floresta, do imprevisível e do instável. Estes dois pólos estão reunidos ou se encontram no reflorestamento, uma obra humana, e se tornam zonas de vizinhança, ou de co-presenças, onde ocorre um tráfego de linhas subjetivas que misturam humanos, vegetais e animais. Osplantios, ao se proporem reflorestamento, podem ser vistos como um devir-floresta proporcionado por esta possibilidade de atrair a floresta, atrair linhas subjetivas que façam misturar novamente aquilo que insistimos em separar. E nisso transitariam, portanto, entre o que chamamos comumente de natureza e cultura.

\footnotetext{
${ }^{14}$ A inserção da designação "agroflorestal" no nome do grupo "Vida e Esperança" não se deveu a uma auto-identificação disseminada entre seus membros, nossos interlocutores, embora tenha se tornado familiar nos últimos anos pela atuação do Centro Yorenka Antame e do "projeto Funbio". 0 ofício de "agroflorestal" está antes consolidado nas Terras Indígenas vizinhas e institucionalizado na Associação do Movimento dos Agentes Agroflorestais Indígenas do Acre (AMAAIAC), havendo políticas públicas estaduais voltadas para este segmento. 0 "projeto Funbio" começou a estabelecer pontes entre esses dois grupos, indígenas e não indígenas, num processo ainda inicial e que não está sendo alvo de reflexão aqui. Sobre o trabalho de formação de agentes agroflorestais indígenas no Acre, consultar, entre outros, Freschi (2004).
}

OS PLANTIOS COMO EXPERIÊNCIA CRIATIVA...

M. C. Pantoja e A. P. de Mattos

$\bullet 165$ 
José Magro, um dos nossos interlocutores e morador do alto rio Caipora, esclareceu que não se trata, com o reflorestamento, de "repor a floresta", coisa "impossível". A floresta, como disse, tem "muitas espécies de vida". Mas também não se trata de instaurar um pomar ou simplesmente plantar fruteiras. Seja num território monótono e "sem" vida, como a pastagem, ou mais diverso, porém empobrecido, como as capoeiras, os plantios instauram o movimento, a riqueza, a multiplicidade de relações. Os animais, por sua mobilidade e capacidade de "invadir" territórios, talvez sejam aquilo que promove uma interação mais evidente e significativa do que estamos tentando indicar aqui. São eles que, ao virem se alimentar, instauram zonas de vizinhança, desterritorializando o espaço ainda bastante humanizado dos plantios.

Um sítio maduro, frutificando, é um lugar certo de visita de animais da mata (como pacas, porcos do mato, cotias, quatipurus, macacos) e pássaros, que dali, tal como nossos interlocutores humanos, se alimentam. São muitos deles parte da dieta alimentar e costumam ser caçados dentro da floresta, mas agora podem ser encontrados dentro dos plantios, e são bem-vindos. Caxixa também insistiu várias vezes conosco para que fossemos apreciar, fotografar e filmar os "micos dourados" que passaram a habitar algumas árvores do seu sítio e com quem havia estabelecido uma relação especial, pois que já o conheciam e não 0 temiam. Eliéti contou, achando graça, sobre os quandus que vem "brincar", como ela mesma disse, nas ingazeiras perto da casa, transformando, ou subvertendo, o espaço doméstico com sua presença selvagem. Nestes dois casos os animais não são consumidos como alimento. Caxixa disse pensar em fazer observações tais como um naturalista, no laboratório em que seu sítio está se tornando. Não só espécies vegetais estão sendo então pesquisadas, mas também os animais que passam mesmo a fazer parte dos plantios.

Assim, os plantios fazem uma ponte entre uma subjetividade mais humana e mais facilmente mapeável, e outras menos claras. Estas esferas de vizinhança articuladas, ou este contínuo subjetivo que liga os espaços da casa, do terreiro, dos roçados e da floresta, envolve não só animais selvagens, mas também outros entes, como os vegetais..$^{15}$ Plantar mudas de árvores ameaçadas por exploração

${ }^{15}$ A perspectiva de um território formado por um conjunto de nichos ecológicos articulados numa economia camponesa florestal foi desenvolvida por Mauro Almeida (1990) para o caso das "colocações". No caso da reflexão aqui em desenvolvimento, estamos priorizando como elemento de articulação dos plantios como território a produção de subjetividades nas relações entre entes 
ilegal, em particular o mogno, é uma forma de aliar-se a elas, e diferenciar-se daqueles que as exploram indiscriminadamente. Chama atenção nas falas uma potência de subjetividade a habitar as madeiras de lei plantadas, seres vivos cujo uso deveria obedecer a regras de preservação da espécie. É interessante observar a quantidade significativa dessas mudas plantadas, que não serão utilizadas por seus plantadores devido ao seu longo ciclo de desenvolvimento. ${ }^{16}$

Palheiras também são constituídas em aliados. Pessoas como Caxixa defendem que não há necessidade de derrubá-las para a retirada das palhas a serem usadas na cobertura de edificações. Apesar de constar do Plano de Utilização da Reserva, esta regra (que prevê inclusive o replantio de palheiras derrubadas) sofre certo abandono. A Caxixa foi possível, a partir desta aliança com as palheiras, estabelecer uma rede que passou a conectar outros moradores vizinhos: apesar de uma resistência inicial, hoje, na localidade Cinco Voltas, onde vivem, a prática de não derrubada das palheiras encontra cada vez mais defensores.

\section{O Conhecimento Tradicional como Alternativa ao Desmatamento}

0 que para nossa ciência régia purificadora (LATOUR, 1994) é uma separação entre dado/natureza/teoria e construído/cultura/prática, para nossos interlocutores é uma pragmática que mistura essas divisões. 0 conhecimento local não produz um território como construído, mas sim como outra coisa. E que coisa é esta? Parece-nos que o que nossos interlocutores fazem é criar uma contrapolítica, ou um fazer político que cria dissenso e resiste à política, cuja tendência é voltar-se para os consensos (SLATER, 2000). Esses recursos criativos, além de escaparem à dependência do Estado, instauram regimes de conhecimento outros que não operam com as divisões científicas. Nossos interlocutores, em suas práticas

\footnotetext{
interespecíficos.

${ }^{16}$ As árvores, no regime de propriedade da Reserva, não são propriamente propriedade privada. De acordo com o sistema de colocações (unidades de exploração e moradia das quais era composto 0 seringal) que inspirou o regime de propriedade nas primeiras Reservas Extrativistas, o seringueiro tinha reconhecida sua autoridade sobre o destino das árvores incidentes naqueles territórios. Mas elas não eram objeto de comercialização, e sim de reciprocidade por meio de trocas, ou mesmo doações (de uma árvore para o fabrico de uma canoa, por exemplo). Este regime de propriedade hoje convive, conflituosamente, com "invasões de madeira", ou seja, casos de exploração predatória e de retirada de árvores sem autorização de seu "proprietário".
}

OS PLANTIOS COMO EXPERIÊNCIA CRIATIVA...

M. C. Pantoja e A. P. de Mattos • 167 
de reflorestamento, trazem para cena o contingente, brincando, ou subvertendo as relações entre natureza e cultura tal como as conhecemos, criando assim outra geopolítica e afirmando a dimensão política do seu conhecimento.

Se para a ciência, e para o Estado, a floresta aparece como o dado e 0 pasto, ou roçado, como construído; se para os projetos de assentamento do Incra (como o existente no rio Amônia) a terra devastada é uma "benfeitoria" de onde se tirará o sustento; no caso dos plantios, não se destrói a floresta para implantálos. Ao lutarem e fazerem de sua experiência (política, subjetiva, de sobrevivência, etc.) uma contra-política que concretiza uma sociocosmologia que faz pouco caso de nossos divisores fundamentais, como natureza/cultura ou sociedade/ natureza, nossos interlocutores propõem alternativas que os diferenciam do que se coloca como inevitável. E na Reserva esta inevitabilidade estaria representada pelo desmatamento em curso e suas causas (pecuária extensiva, agricultura comercial, adensamento populacional etc).

Na perspectiva adotada aqui, buscamos evidenciar como a mistura que caracteriza os conhecimentos tradicionais em sua produção de novos territórios se opõe aos processos de subjetivação associados ao desmatamento como uma forma de territorialização. Os "sistemas agroflorestais" e outros instrumentos de conhecimentos técnicos e externos são resignificados pelo regime de conhecimento local, constituindo os plantios numa alternativa sólida ao desmatamento. ${ }^{17}$

A floresta e seus entes são tomados não apenas como recursos naturais que garantem a sobrevivência dos humanos, mas como sujeitos de direito com subjetividades potenciais. ${ }^{18}$ Esta imagem da floresta como potência subjetiva, como

${ }^{17}$ Há, claro, dificuldades em traduzir produções tais como os plantios e sua potência de subjetivação em instrumentos legais de garantia de direitos. Por outro lado, não resta dúvida que os conhecimentos tradicionais tem se tornado cada vez mais, como aponta Alfredo Wagner Berno de Almeida (2010, p. 15), "uma categoria do direito e um instrumento político de defesa dos territórios". Almeida (2010, p. 16) reconhece que a "normatização dos conhecimentos tradicionais [...] é produto de imposições mercantis e de políticas econômicas dirigidas para o uso do patrimônio genético do planeta".

${ }^{18}$ A ideia de subjetividades a habitar outros seres vivos que não só os humanos, os regimes de conhecimento associados a ela e a "sociedade" (e a "natureza") que se desenha, ou se esvanece, a partir desta perspectiva, bem como os efeitos disso tudo sobre a própria Antropologia foram abordados num artigo hoje clássico de Eduardo Viveiros de Castro (1996). A partir desta referência, Carla Dias (2004) escreveu sobre as relações entre caçadores e caça na Reserva Extrativista do Alto Juruá. 
multiplicidade de vida, ainda que agora venha recoberta de um discurso ecológico, recheada de conceitos da biologia, da agronomia, da antropologia, não deixa (por outro lado) de ser a retomada, ainda que discreta, das ciências nativas da mistura, e isso só é possível num terreno propício como o terreno cultural amazônico.

Finalmente, recordemos que, em novembro de 2011, quando da escolha do nome coletivo sob o qual se reuniriam, o primeiro nome proposto foi "saberes da floresta", descartado pela homonímia com Centro Yorenka Antame. Não se trata de coincidência ou plágio, há uma real admiração e identificação com o trabalho dos indígenas da região. 0 nome afinal escolhido foi "Vida e Esperança", o que remete a uma expressão comumente utilizada para definir o trabalho do grupo: "vida construindo vida", ou "vida colocando vida".

Esta frase, que aqui e ali estamos sempre ouvindo quando o tema é a definição do trabalho que fazem com os plantios, evoca a conexão para a qual seguidamente chamamos atenção aqui entre humanos e outras subjetividades, e mesmo a necessidade de afirmar que, na floresta, não são apenas os humanos que têm vida. Esta expressão, portanto, estaria associada a capacidades tais como sentir, pensar ou ser sujeito de direitos. A noção de esperança, por sua vez, não se restringe à esperança de que essas outras subjetividades não sejam extintas (atente-se para que já não falamos de espécies), mas que se extinga esse vínculo intersubjetivo que faz deles mesmos quem eles são e os diferencia daqueles que dele abdicaram.

\section{REFERÊNCIAS}

ALLEGRETTI, Mary. A construção social de políticas ambientais. Chico Mendes e o Movimento dos Seringueiros. 2002. Tese (Doutorado em Desenvolvimento Sustentável) - Centro de Desenvolvimento Sustentável, Universidade de Brasília, Brasília, 2002.

ALMEIDA, Alfredo Wagnet Berno (Org.). Conhecimentos tradicionais e territórios na Pan-Amazônia. Manaus: PNCSA/UEA, 2010.

ALMEIDA, Alfredo Wagnet Berno. Carajás: a guerra dos mapas. Belém: Seminário Consulta, 1995. 
. Universalização e localismo: movimentos sociais e crise dos padrões tradicionais de relação política na Amazônia. Reforma Agrária, ano 19, n. 1, p. 4-16, abr./jul. 1989.

ALMEIDA, Mauro William Barbosa. As colocações como forma social, sistema tecnológico e unidade de recursos naturais. Terra Indígena, Araraquara, ano 7, n. 54, p. 29-39, 1990.

. Caipora, mandioca e outros conflitos ontológicos. São Carlos, 2007. Palestra proferida no Departamento de Antropologia, Universidade Federal de São Carlos.

0 Estatuto da terra e as reservas extrativistas. Reforma Agrária, Campinas v. 25, n. 1, p. 153-168, jan./abr. 1995.

Redescobrindo a família rural. Revista Brasileira de Ciências Sociais, São Paulo, n. 1, p. 66-83, 1986.

CARNEIRO DA CUNHA, Manuela. Cultura com aspas e outros ensaios. São Paulo: Cosac Naify, 2009.

CARNEIRO DA CUNHA, Manuela; ALMEIDA, Mauro W. B. de (Org.). Enciclopédia da floresta. 0 Alto Juruá: práticas e conhecimentos das populações. São Paulo: Companhia das Letras, 2002.

DELEUZE, Gilles; GUATTARI, Felix. Mil platôs: capitalismo e esquizofrenia. São Paulo: Ed. 34, 1997. v. 5.

DIAS, Carla. Na floresta onde vivem mansos e brabos: economia simbólica de acesso à natureza praticada na reserva extrativista do Alto Juruá - Acre. 2004. Dissertação (Mestrado em Antropologia) - Universidade Estadual de Campinas, Campinas, 2004.

ERINGHAUS, Christiane; GOMES, Carlos Valério. Implicações da pecuária em reservas extrativistas. Brasília: Oficina Técnica MMA/DAAM/ICMBio-GTZ, 2008. Mimeografado.

FRESCHI,Julieta M. Autoria, interculturalidade e conhecimentos etnoecológicos: o caso dos agentes agroflorestais indígenas do Acre. 2004. Dissertação (Mestrado em Desenvolvimento Sustentável) - Centro de Desenvolvimento Sustentável, Universidade de Brasília, Brasília, 2004. 
GOLDMAN, Márcio. Introdução: políticas e subjetividades nos "novos movimentos culturais." Ilha Revista de Antropologia, Florianópolis, v. 9, n. 1, 2, p. 8-22, 2009. IGLESIAS, Marcelo P. Os Kaxinawá de Felizardo: correrias, trabalho e civilização no Alto Juruá. Brasília: Paralelo 15, 2010.

LATOUR, Bruno. Jamais fomos modernos. São Paulo: Ed. 34, 1994.

PANTOJA, Mariana Ciavatta et al. (Org.). Enciclopédia da floresta: 0 alto juruá: práticas e conhecimentos das populações. São Paulo: Companhia das Letras, 2002. PANTOJA, Mariana Ciavatta. Os Milton: cem anos de história nos seringais. Rio Branco: Edufac, 2008.

PANTOJA, Mariana Ciavatta; COSTA, Eliza M. L.; POSTIGO, Augusto. A presença do gado em reservas extrativistas: algumas reflexões. Revista Pós Ciências Sociais, São Luis, v. 6, n. 12, p. 115-130, 2009.

SLATER, David. Repensando as espacialidades dos movimentos sociais: questões de fronteiras, cultura e política em tempos globais. In: ALVAREZ, Sonia E.; DAGNINO, Evelina; ESCOBAR, Arturo (Org.). Cultura e política nos movimentos sociais latino-americanos: novas leituras. Belo Horizonte: Ed. da UFMG, 2000.

VIVEIROS DE CASTR0, Eduardo. A inconstância da alma selvagem e outros ensaios de antropologia. São Paulo: Cosac Naify, 2002.

. Eduardo. Os pronomes cosmológicos e o perspectivismo ameríndio. Mana, n. 2/2, p. 115-144, 1996.

VIVEIROS DE CASTRO, Eduardo; GOLDMAN, Márcio. 0 que pretendemos é desenvolver conexões transversais. In: SZTUTMAN, Renato (Org.). Encontros: Eduardo Viveiros de Castro. Rio de Janeiro: Beco do Azougue, 2008.

WAGNER, Roy. A invenção da cultura. São Paulo: Cosac Naify, 2010.

WOLFF, Cristina S. Mulheres da floresta. São Paulo: Hucitec, 1999. 